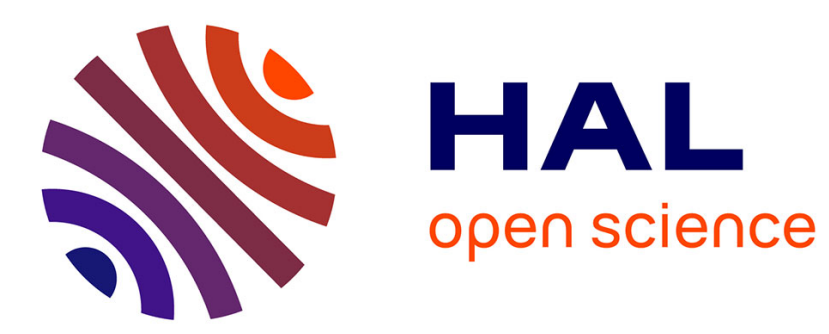

\title{
Vieillissement et territoires : une typologie essentielle Gérard-François Dumont
}

\section{To cite this version:}

Gérard-François Dumont. Vieillissement et territoires: une typologie essentielle. Population et avenir, 2013, 711, pp.3. 10.3917/popav.711.0003 . halshs-00783506

\section{HAL Id: halshs-00783506 https://shs.hal.science/halshs-00783506}

Submitted on 1 Feb 2013

HAL is a multi-disciplinary open access archive for the deposit and dissemination of scientific research documents, whether they are published or not. The documents may come from teaching and research institutions in France or abroad, or from public or private research centers.
L'archive ouverte pluridisciplinaire HAL, est destinée au dépôt et à la diffusion de documents scientifiques de niveau recherche, publiés ou non, émanant des établissements d'enseignement et de recherche français ou étrangers, des laboratoires publics ou privés. 


\section{Vieillissement et territoires : une typologie essentielle}

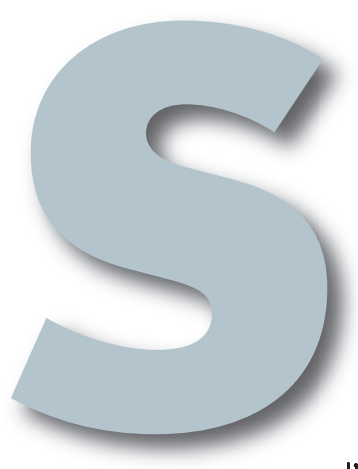

\author{
par Gérard-François \\ DUMONT
}

ur chaque territoire, les évolutions démographiques modifient à la fois le nombre des habitants et leur composition par âge. Ce qui est vrai pour l'ensemble de la population d'un territoire l'est aussi pour sa population âgée. II en résulte, pour ce qu'il est convenu d'appeler le vieillissement de la population, quatre types d'évolution possibles.

Ces types se distinguent selon la façon dont se combinent les effets de flux et de structure concernant les personnes âgées.

Les effets de structure se traduisent par un vieillissement, au sens mathématique ou stricto sensu du terme et non au sens général employé ci-dessus, ou un rajeunissement du territoire selon la combinaison des quatre facteurs du vieillissement, soit le vieillissement « par le bas », le vieillissement « par le haut », le système migratoire du territoire et son héritage démographique ${ }^{1}$. Autrement dit, un territoire peut connaître :

- soit un vieillissement de sa population lorsque le pourcentage des personnes âgées dans sa population totale augmente ;

- soit un rajeunissement de sa population lorsque le pourcentage des personnes âgées dans sa population totale diminue.

Concernant les effets de flux qui méritaient d'être dénommés, nous avons imaginé le néologisme " gérontocrois sance $^{2}$ » et son contraire, la gérontodécroissance. Un territoire connaît donc :

- une gérontocroissance lorsque son nombre de personnes âgées augmente ;

- et, à l'inverse, une gérontodécroissance lorsque son nombre de personnes âgées diminue.

La combinaison des deux types d'effets de structure et des deux types d'effets de flux conduit à mettre en évidence quatre types d'évolutions possibles selon les territoires : ils sont présentés dans le tableau ci-contre. Ce tableau donne en outre des exemples de territoires français, départements ou communes, en considérant la période intercensitaire allant du dernier recensement général de la population de la France, celui de 1999, au recensement de la population de 2008.

\section{LES QUATRE TYPES DE VIEILLISSEMENT SELON LES TERRITOIRES}

\begin{tabular}{|c|c|c|}
\hline & $\begin{array}{c}\text { Vieillissement } \\
= \\
\text { Augmentation du \% } \\
\text { des } 65 \text { ans ou plus } \\
\text { dans la population totale } \\
\text { du territoire }\end{array}$ & $\begin{array}{c}\text { Rajeunissement } \\
= \\
\text { Diminution du \% } \\
\text { des } 65 \text { ans ou plus } \\
\text { dans la population totale } \\
\text { du territoire }\end{array}$ \\
\hline $\begin{array}{c}\text { Gérontocroissance } \\
= \\
\text { Augmentation des } \\
\text { personnes âgées } \\
\text { dans la population totale } \\
\text { du territoire }\end{array}$ & $\begin{array}{l}\text { Vieillissement et } \\
\text { Gérontocroissance } \\
\text { Exemples : } \\
\text { Hautes-Alpes } \\
\text { Essonne }\end{array}$ & $\begin{array}{l}\text { Rajeunissement et } \\
\text { Gérontocroissance } \\
\text { Exemples : } \\
\text { Ariège } \\
\text { Haute-Garonne }\end{array}$ \\
\hline $\begin{array}{l}\text { Gérontodécroissance } \\
= \\
\text { Diminution des } \\
\text { personnes âgées } \\
\text { dans la population totale } \\
\text { du territoire }\end{array}$ & $\begin{array}{l}\text { Vieillissement et } \\
\text { Gérontodécroissance } \\
\text { Exemples : } \\
\text { Brest } \\
\text { Montluçon }\end{array}$ & $\begin{array}{l}\text { Rajeunissement et } \\
\text { Gérontodécroissance } \\
\text { Exemples: } \\
\text { Creuse } \\
\text { Paris }\end{array}$ \\
\hline
\end{tabular}

Cette méthode permettant de distinguer quatre types d'évolution du vieillissement des territoires est un plaidoyer pour une application intelligente du principe de subsidiarité. D’une part, tout territoire doit déployer une politique des âges ${ }^{3}$ prenant en compte les personnes âgées ainsi que la solidarité nécessaire et souhaitable entre les générations. D’autre part, la mise en œuvre territoriale des politiques nationales des âges doit s'adapter à la diversité des types de vieillissement.

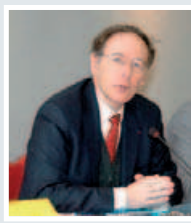

Dumont Gérard-Francois et alii Les territoires face au vieillissement en France eten Europe, Paris, Ellipses, 2006. Cf. également « Vieillissement et teritoires », Population \& Avenir, $n^{\circ} 674$ bis, septembre-octobre 2005. 2. Termes entrés dans plusieurs dictionnaires; cf. Wackermann, Gabriel (direction), Dictionnaire de Géographie, Paris, Ellipses, 2005 ; Environnement et société, Paris, Ellipses, 2011.

3. Dumont, Gérard-François, «Pour une politique des âges », Population \& Avenir, $n^{\circ} 675$, novembre-décembre 2005

\section{Toxjours soucieuse d'être à la sointe dans une analyse claire et argumentét des posulations et des territoires, \\ la revue Dosulation \& Avenirvous remercie de votre fidélité et rous souhaite une bonne année 2013.}

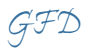

